This work was funded by the Sir Halley Stewart Trust and the MRC (Grant G9217174PB). We also wish to thank Meg Stark for the photography. Address correspondence to Roger Hall, Department of Biology, University of York, P.O. Box 373, York, England YO1 5YW, UK. Internet: frh1@unix.york.ac.uk

Received 26 October 1995; accepted 27 November 1995.

Carol A. Gilchrist, Helen L. Streets, John P. Ackers ${ }^{1}$ and Roger Hall

University of York, York

${ }^{1}$ London School of Hygiene and Tropical Medicine London, England, UK

\section{LA-PCR-Based Quick Method for the Identification of Genes Responsible for the Complementation of Saccha- romyces cerevisiae Mutations}

BioTechniques 20:772-778 (May 1996)

Cloning of Saccharomyces cerevisiae genomic DNAs that complement yeast mutations includes (i) screening of genomic DNA library clones by complementation and (ii) identification of the DNA regions essential for the complementation ability. Since commonly used yeast genomic DNA libraries made on YEp-type (2) or YCptype (6) plasmids harbor about $10 \mathrm{~kb}$ of yeast chromosomal DNA, the inserted yeast DNA usually contains several genes. Frequently, to identify the candidate gene on a plasmid essential for the complementation, subcloning analysis is carried out. However, this step is laborious, dependent on the physical map, and sometimes time consuming. Transposon mutagenesis also is used, but with either method, one has to know the physical map of the inserted DNA in advance.

The current protocol was developed in order to replace the subcloning step during cloning of yeast genes. It consists of screening transposon-mutagenized plasmids that do not complement the mutation and determination of the position of transposon insertions with the LA (long and accurate) polymerase chain reaction (PCR) method $(1,3)$. LA-PCR is applicable here because even the entire 10-kb DNA fragment can be amplified with this technique. Direct sequencing of the LA-PCR products makes it possible to determine the DNA sequence of the cloned genes. Bacterial transposition, combined with the LA-PCR method, allows easy identification of complementing yeast genes without any restriction enzyme digestion. To show the utility of this protocol, I demonstrate here mapping of the yeast calmodulin gene, CMD1, on a pST26 plasmid (Figure 1), which was isolated from a YEp13-based genomic library (10).

\section{Tn5-Mutagenesis of pST26 with pCHR81}

To isolate insertion mutations, I used transposon Tn5, since Tn5 transposes at high frequency and with relatively little target sequence specificity. A stringent plasmid, pCHR81, which harbors $\operatorname{Tn} 5$, has been used to isolate Tn5 insertion mutations (8). E. coli strain $\mathrm{DH} 5 \alpha \mathrm{F}^{\prime}$ (pCHR81) was cultured at $30^{\circ} \mathrm{C}$ in $\mathrm{LB}+10 \mu \mathrm{g} / \mathrm{mL} \mathrm{Km}$ (kanamycin) and harvested to make competent cells for transformation (7). The cells were transformed with pST26, which is a variant of YEp13 harboring bla (ampicillin-resistant), a relaxed-type plasmid origin and an approximately $10-\mathrm{kb}$ yeast genomic insert at the BamHI site of the Tc (tetracycline) gene (Figure 1). Transformants were selected on $\mathrm{LB}+10 \mu \mathrm{g} / \mathrm{mL} \mathrm{Km}+$ $60 \mu \mathrm{g} / \mathrm{mL} \mathrm{Ap} \mathrm{(ampicillin)} \mathrm{at} 30^{\circ} \mathrm{C}$.

Cells from 48 colonies were inoculated separately in $1 \mathrm{~mL}$ of $\mathrm{LB}+200$ $\mu \mathrm{g} / \mathrm{mL} \mathrm{Km}+60 \mu \mathrm{g} / \mathrm{mL} \mathrm{Ap}$ and incubated at $37^{\circ} \mathrm{C}$ for $24 \mathrm{~h}$. For this purpose, I used microplates with 24 wells (No. 662160, Greiner, Germany) incubated on a rotator with an 8-shaped track (Rikakikai, Tokyo, Japan). Since the replication of pCHR81 was temper-

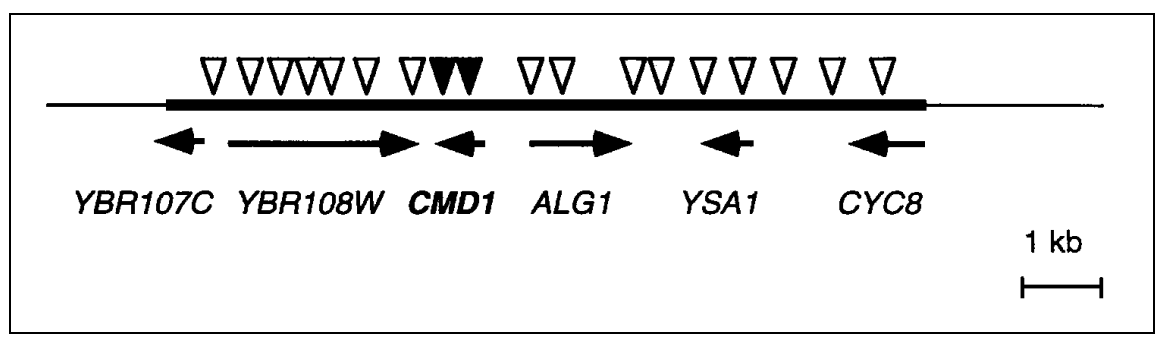

Figure 1. Yeast genomic DNA insert of pST26. Thick and thin bars represent yeast DNA sequence and YEp13 sequence, respectively. Yeast ORFs predicted by the DNA sequences of chromosome II (4) are shown in arrows. Positions of Tn5 insertions that complemented cmdl (open triangles) or did not complement $\mathrm{cmdl}$ (closed triangles) are shown above the thick line. 
ature-sensitive, only $E$. coli cells that had undergone transposition of $\operatorname{Tn} 5$ could grow. In addition, cells containing mutagenized plasmids accumulated, since only cells with multiple copies of Tn5 grew in the presence of a high concentration of $\mathrm{Km} \mathrm{(200}$ $\mu \mathrm{g} / \mathrm{mL})$. Tubes of the culture were combined, and small-scale isolation of plasmids was performed (7). The miniprep plasmids were used to transform $\mathrm{DH} 5 \alpha \mathrm{F}^{\prime}$. bla-kan colonies were selected on $\mathrm{LB}+200 \mu \mathrm{g} / \mathrm{mL} \mathrm{Km}+60$ $\mu \mathrm{g} / \mathrm{mL} \mathrm{Ap}$ at $37^{\circ} \mathrm{C}$ and used for minipreparation of DNA to obtain 48 plasmid solutions, each containing a single kind of mutagenized plasmid.

\section{Determination of Position of Trans- poson with LA-PCR}

Mutagenized plasmids were used to transform YOC228, which possessed a temperature-sensitive calmodulin mutation (5). Among the 48 mutagenized plasmids examined, two plasmids did not complement the cmdl mutation. Since construction of a series of mutagenized libraries requires many plasmid DNA preparations, I tried to simplify this process by using a mixture of mutagenized plasmids for yeast transformation, similar to a genetic footprinting strategy (9). But this was not feasible because of the high frequency of spontaneous mutations during transformation.

The position of transposon insertions, which disrupted the $C M D 1$ gene, was determined with LA-PCR $(1,3)$. To amplify the DNA fragment between the left end of the yeast DNA and the insertion site of Tn5, I used a primer (Tc-N: atc gac tac geg atc atg geg acc aca ccc gtc ct) specific for the tetracycline gene and a second primer (Tn5-33R: ggt tcc gtt cag gac get act tgt gta taa gag tc) specific for the repetitive sequence of Tn5. Long DNA fragments were ampli- fied to give a high yield with ExTaq ${ }^{\mathrm{TM}}$ (Takara, Kyoto, Japan) using a buffer recommended by the manufacturer. The final reaction volume was $50 \mu \mathrm{L}$ and contained $0.2 \mu \mathrm{g}$ of each of the primers and $1 \mu \mathrm{L}$ of mini-prep DNA as a template. The reaction was taken through 30 cycles in the thermal cycler PTC-200 DNA Engine ${ }^{\mathrm{TM}}$ (MJ Research, Watertown, MA, USA): each cycle consisted of $94^{\circ} \mathrm{C}$ for $20 \mathrm{~s}$ (denaturation) and $68^{\circ} \mathrm{C}$ for 4 min (annealing and extension).

The LA-PCR products were analyzed with $0.7 \%$ agarose gel electrophoresis (Figure 2). A mixture of the mutagenized plasmids gave a number of discrete bands ranging from $0.4 \mathrm{~kb}$ to over $10 \mathrm{~kb}$ showing that Tn5 transposed into many positions in the plasmid. Insertion mutations that did not complement the cmdl mutation were mapped at $3.5 \mathrm{~kb}$ and $3.8 \mathrm{~kb}$ from the left end of the yeast DNA. Insertion positions that did not disrupt CMD1 function are shown as open triangles in Figure 1. These results completely matched the genomic structure of the yeast DNA of pST26.

The LA-PCR products were purified with DNA Prep ${ }^{\mathrm{TM}}$ (Daiayatoron, Tokyo, Japan), after agarose gel electrophoresis, and used for DNA sequencing with a primer (Tn5-Seq: ggt tcc gtt cag gac gct ac) specific for the repetitive sequence of Tn5. DNA sequencing analysis indicated that Tn5 was, in fact, inserted in the CMDl gene $106 \mathrm{bp}$ and $412 \mathrm{bp}$ downstream of the initiation codon.

This experimental approach to

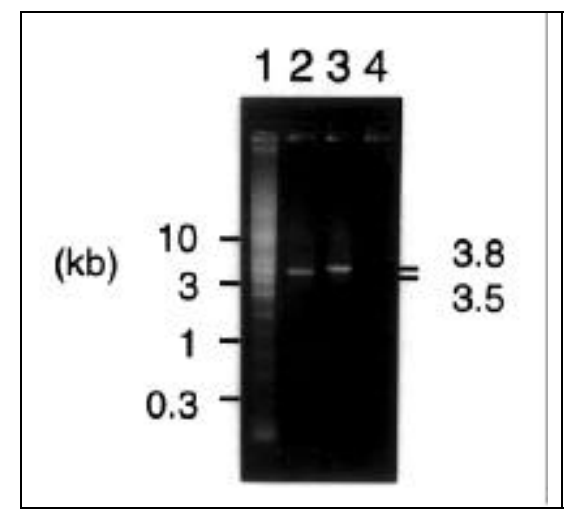

Figure 2. Agarose gel electrophoresis of LAPCR products. A mixture of mutagenized pST26 (lane 1), two plasmids that did not complement $\mathrm{cmdl}$ (lanes 2 and 3) and pST26 (lane 4) were used as templates. 
analyzing the gene of interest has several advantages over subcloning analysis. This method does not require any information about physical maps of the insert DNA. Positions of transposon insertion are presented as a distance from one end of the genomic DNA. Even if the restriction map is known, this technique should be preferable because of its simplicity. Using this protocol, it takes only one week to identify the region essential for the complementation. Furthermore, restriction digestion or ligation reaction is not necessary to determine the partial DNA sequence of the gene. Therefore, with this protocol, one can reduce the time required for DNA cloning and move on to the functional analysis of the gene. Finally, this protocol should prove useful for cloning in other organisms in which cloning by complementation is popular.

\section{REFERENCES}

1.Barnes, W.M. 1994. PCR amplification of up to 35-kb DNA with high fidelity and high yield from lambda bacteriophage templates. Proc. Natl. Acad. Sci. USA 91:2216-2220.

2.Carlson, M. and D. Botstein. 1982. Two differentially regulated mRNAs with different $5^{\prime}$ ends encode secreted and intracellular forms of yeast invertase. Cell 28:145-154.

3.Cheng, S., C. Fockler, W.M. Barnes and R. Higuchi. 1994. Effective amplification of long targets from cloned inserts and human genomic DNA. Proc. Natl. Acad. Sci. USA 91:5695-5699.

4.Feldmann, H., M. Aigle, G. Aljinovic, B. Andre, M.C. Baclet, C. Barthe, A. Baur, A.M. Becam et al. 1994. Complete DNA sequence of yeast chromosome II. EMBO J. 13:5795-5809.

5.Ohya, Y. and D. Botstein. 1994. Diverse essential functions revealed by complementing yeast calmodulin mutants. Science 263:963966.

6.Ohya, Y., S. Miyamoto, Y. Ohsumi and Y. Anraku. 1986. Calcium-sensitive cls4 mutant of Saccharomyces cerevisiae with a defect in bud formation. J. Bacteriol. 165:28-33.

7.Sambrook, J., E.F. Fritsch and T. Maniatis. 1989. Molecular Cloning: A Laboratory Manual, 2nd ed. Cold Spring Harbor Laboratory Press, Cold Spring Harbor, NY.

8.Sasakawa, C. and M. Yoshikawa. 1987. A series of Tn5 variants with various drug-resistance markers and suicide vector for transposon mutagenesis. Gene 56:283-288.

9.Smith, V., D. Botstein and P.O. Brown. 1995. Genetic footprinting: a genomic strategy for determining a gene's function given its sequence. Proc. Natl. Acad. Sci. USA 92:6479-6483.

10.Yoshihisa, T. and Y. Anraku. 1989. Nucleotide sequence of $A M S 1$, the structure gene of vacuolar alpha-mannosidase of Saccharomyces cerevisiae. Biochem. Biophys. Res. Commun. 163:908-915.

I would like to thank Dr. C. Sasakawa, Dr. D. Johnson and S. Terui for the plasmids, Y. Takita for the oligonucleotides and $K$. Richards for reading the manuscript. Address correspondence to Yoshikazu Ohya, Department of Biological Sciences, Graduate School of Science, University of Tokyo, Hongo, Bunkyo-ku, Tokyo 113 Japan. Internet:ohya@uts2.s.u-tokyo.ac.jp

Received 26 September 1995; accepted 16 November 1995.

\section{Yoshikazu Ohya \\ University of Tokyo \\ Tokyo, Japan}

\section{Identification of Introns by Reverse-Transcription PCR}

BioTechniques 20:778-780 (May 1996)

Analysis of previously unidentified genes is often begun by screening an expression library with a specific antibody or screening a cDNA library with a heterologous probe. The advantage of using cDNA libraries is that the identified clone will contain only coding sequences. However, there are three instances where the use of a cDNA library is not practical. First, if the gene under investigation is a regulatory gene and the level of mRNA is low, the gene might not be represented in the cDNA library. Second, if the gene is long and the first-strand cDNA synthesis did not go to completion, the $5^{\prime}$ region of the gene might not be represented in the library. Third, if the gene has a developmentally regulated pattern of expression or a limited tissue specificity, it is possible that the cDNA library does not represent the time or tissue specificity of peak expression of the gene, thus minimizing the chance of finding the clone in an available library.

Cloning from a genomic library or directly from a genomic DNA preparation can circumvent all these problems.
However, there is always the possibility that the genomic clone will contain intervening sequences. These sequences are currently identified by comparing the sequence of genomic and cDNA clones. However, as stated above, cDNA clones are not always available. In the following note, we suggest a rapid and accurate method to identify introns within a cloned genomic sequence in the absence of a cDNA clone.

In our efforts to identify the Dictyostelium homolog of the primate UVdamaged DNA-binding (UV-DDB) protein (1), we screened a cDNA library and identified a series of positive partial clones representing a 1.6-kb 3' end of the gene. An exhaustive screen of the library did not reveal any longer clones. We therefore constructed a detailed restriction map of the region

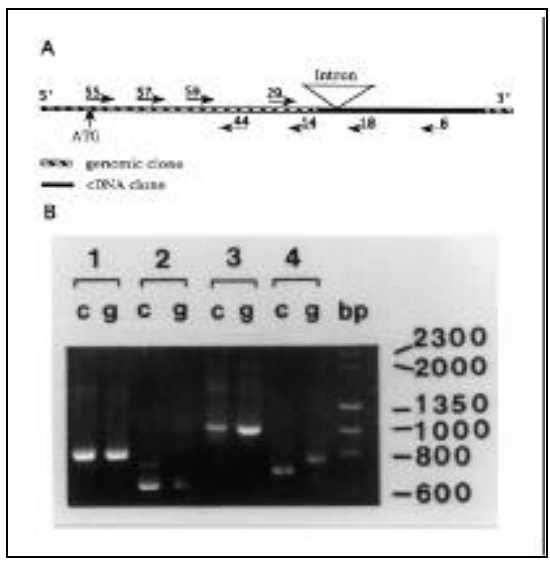

Figure 1. A) Schematic presentation of the $r e p \mathrm{E}$ gene. Oligonucleotides that were used for PCR are depicted by arrows. Oligo \#6 was used for reverse-transcription (RT)-PCR. The position of the 92-bp intron is shown. B) PCR amplification of genomic DNA and cDNA. PCR was performed using a Coy Laboratory Products thermal cycler (Grass Lake, MI, USA) for 30 cycles under the following conditions: 1-min denaturation at $94^{\circ} \mathrm{C}, 2$-min annealing at $40^{\circ} \mathrm{C}$ and 3-min elongation at $72^{\circ} \mathrm{C}$. The last elongation was extended to $10 \mathrm{~min}$. Each reaction contained $2 \mu \mathrm{L}$ of 20 $\mu \mathrm{M}$ primers, $10 \mu \mathrm{L}$ of $2.5 \mathrm{mM}$ dNTP and $1 \mu \mathrm{L}$ Taq DNA polymerase (AmpliTaq ${ }^{\circledR}$; PerkinElmer, Norwalk, CT, USA) in buffer containing $20 \mathrm{mM}$ Tris- $\mathrm{HCl}, \mathrm{pH} 8.4,50 \mathrm{mM} \mathrm{NaCl}$ and 1.5 $\mathrm{mM} \mathrm{MgCl}$. For the amplifications of genomic sequences, we used 2-3 $\mu \mathrm{g}$ of total Dictyostelium genomic DNA per reaction. For the amplification of the cDNA, we used $2.2 \mu \mathrm{L}$ of the RT reaction, following the instruction in the kit. The following sets of primers were used: set 1 , primer $44 \rightarrow$ primer 55 ; set 2 , primer $44 \rightarrow$ primer 57 ; set 3 , primer $14 \rightarrow$ primer 59 and set 4 , primer $10 \rightarrow$ primer 29. In each set, left lane represents cDNA (c) and right lane represents genomic DNA (g). Molecular weight markers are indicated. 